African Crop Science Journal by African Crop Science Society is licensed under a Creative Commons Attribution 3.0 Uganda License. Based on a work at www.ajol.info/ and www.bioline.org.br/cs DOI: https://dx.doi.org/10.4314/acsj.v27i2.3

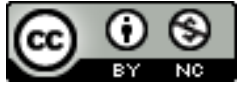

\title{
ESTIMATES FOR HERITABILITY AND CONSUMER-VALIDATION OF A PENETROMETER METHOD FOR PHENOTYPING SOFTNESS OF COOKED CASSAVA ROOTS
}

\section{P. IRAGABA, E. NUWAMANYA ${ }^{1}$, E. WEMBABAZI ${ }^{1}$,Y. BAGUMA ${ }^{1}$, D. DUFOUR ${ }^{2}$, E.D. EARLE, R.B. KERR ${ }^{3}$,H.A. TUFAN, M.A. GORE and R.S. KAWUKI ${ }^{1}$}

Plant Breeding and Genetics Section, School of Integrative Plant Science, Cornell University, Ithaca, NY 14853, USA

${ }^{1}$ National Crops Resources Research Institute (NaCRRI), P. O. Box 7084, Kampala, Uganda ${ }^{2}$ Centre de Coopération Internationale en Recherche Agronomique pour le Développement, CIRAD, UMR Qualisud, 34398 Montpellier, France ${ }^{3}$ Department of Development Sociology, Cornell University, Ithaca, NY 14853, USA

Corresponding author: kawukisezirobert@gmail.com

(Received 29 October 2018; accepted 10 May 2019)

\begin{abstract}
Although breeders have made significant progress in the genetic improvement of cassava (Manihot esculenta Crantz) for agronomic traits, lack of information on heritability and limited testing of highthroughput phenotyping methods are major limitations to improving root quality traits, such as softness after cooking, which rank high among Ugandan consumers. The objectives of this study were to determine heritability for softness of cooked cassava roots, and quantify the relationship between penetrometer and consumer testing methods for phenotyping softness of cassava roots. Softness defined as the maximum force $(\mathrm{N})$ needed to penetrate cooked root samples using a penetrometer, was evaluated at four cooking time intervals: 15, 30, 45, and $60 \mathrm{~min}$ on 268 cassava genotypes. Estimates of broad-sense heritability (repeatability) ranged from 0.17 to 0.37 , with the highest value observed at 45 min of cooking time interval. In the second study involving 135 cassava consumers from Kibaale district in Uganda, penetrometer measurements of cooked roots from six cassava varieties were found to be in strong agreement $\left(r^{2}=0.91 ; P\right.$-value $\left.=0.003\right)$ with ordinal scores of root softness from consumer testing. These results suggest that: (a) softness of cooked cassava roots is a trait amenable for evaluation and selection; and (b) a penetrometer can readily be used for assessment of cooked root softness. These findings form the basis for operationalising the routine assessment of root softness in cassava breeding trials, an output that will enhance ongoing efforts to breed for desired end-user root quality traits.
\end{abstract}

Key Words: Breeding, cooking, Manihot esculenta 
Les sélectionneurs ont fait des progrès considérables dans l'amélioration génétique des caractères agronomiques du manioc (Manihot esculenta Crantz). Cependant un manque de méthodes de phénotypage haut-débit adaptées aux caractères de qualités tel que la fermeté de la racine après cuisson, essentiel pour les consommateurs Ougandais. Cette étude ambitionne a) de determiner l'héritabilité de la fermete de racine cuite b) de quantifier la relation entre lévaluation de la fermeté de racine cuite au pénétromètre et un panel consommateurs. Cette évaluation a été realisee a quatre intervals de temps: 15, 30, 45 et 60 minutes sur 268 genotypes de manioc. Pour définir l'héritabilité de la fermeté de la racine, celle ci a été définie par la force maximum $(\mathrm{N})$ nécessaire pour pénétrer des échantillons de racines incluant diffèrent temps de cuisson $(15,30,45$, and $60 \mathrm{~min})$ a l'aide d'un pénétromètre. L'héritabilité au sens large (ou répétabilité) observée varie de 0.17 a 0.37 , la valeur la plus élevé étant observée pour un temps de cuisson de 45 minutes. Dans une seconde étude impliquant 135 consommateurs du district de Kibaale (Ouest de l'Ouganda), les mesures au pénétromètre de racines cuites de six variétés ont confirmées la forte correlation $\left(r^{2}=0.91 ; P\right.$-value $\left.=0.003\right)$ avec les valeurs ordinales de fermeté de racine du panel consommateur. Les résultats de cette étude indiquent que cette méthodologie de phénotypage est a) utile pour l' évaluation de la fermeté sur des racines cuites en selection et b) démontre que l'usage du pénétromètre est efficace pour celle ci. Ces résultats offrent aux sélectionneurs une methode d' évaluation de routine de la qualite de racine pour les essais experimentaux. Ceux ci contribueront aux efforts actuels pour l'amélioration des caractères qualités chers aux consommateurs.

Mots Clés: sélection variétale, cuisson, Manihot esculenta

\section{INTRODUCTION}

Cassava (Manihot esculenta Crantz) is an important source of food for about 800 million people worldwide (FAO and IFAD, 2000; Lebot, 2009; FAO, 2013). With a high diversity of end-users, cassava varieties that are released without a focus on product quality may not meet end-user trait preferences and are thus poorly adopted by farmers (Chiwona-Karltun et al., 2015; Bechoff et al., 2018a). In a variety adoption study conducted in Malawi, only $7 \%$ of improved cassava varieties tolerant to African cassava mosaic disease were adopted, simply because the new varieties lacked consumption quality attributes desired by end-users (Alene et al., 2013). In a related study conducted in the Republic of Congo, farmers abandoned varieties that did not meet both their agronomic and culinary trait preferences (Kombo et al., 2012). These results highlight the critical role of end-users in variety development and adoption.
In Uganda, traits such as high yield and cooking quality justify farmers' variety choices and hence historic cultivation of cassava varieties (Nakabonge et al., 2017). End-user traits such as softness of cooked cassava roots have been reported to be highly preferred by consumers (Ngeve, 2003; Padonou et al., 2005). As a top trait emerging from consumer surveys, we consider softness as an important breeding criterion to respond to the needs of cassava farmers and consumers in Uganda.

One major limitation to breeding end-user culinary root quality traits such as cassava root softness is the lack of reliable, low-cost and accurate high-throughput methods for assessing root softness in clones under evaluation. Consequently, consumer acceptability testing, which involve assessing the perception of consumers regarding the new products, is used as a fallback by most breeding programmes as a method to determine culinary root quality traits (Bechoff et al., 2018b). Unfortunately, consumer acceptability 
testing of culinary root quality traits is not ideal in early selection stages that are often associated with a large number of entries (IITA, 1990; Ceballos et al., 2004). Moreover, consumer acceptability studies require significant amounts of resources in terms of time, funds and personnel, further complicating the selection process. It is for this reason that most culinary root quality traits are scored later in the selection process, using a group of consumers that is tasked to evaluate only a few advanced breeding lines (Ceballos et al., 2004). A major disadvantage of this approach may be the unintended loss of genetic variation for culinary root quality traits during the early selection process (Ceballos et al., 2004; Bernardo, 2010). These shortfalls justify the urgent need to develop alternative phenotyping methods which can be used on a large number of lines and are well correlated with consumer acceptance.

Most of the previous studies on softness of cooked cassava roots have focused on food quality and with few samples i.e., $(n<25)$ (Eggleston and Asiedu, 1994; Ngeve, 2003; Padonou et al., 2005; Sajeev et al., 2010). None of these studies estimated heritability of cassava root softness. Information on heritability estimates (in this case for root softness) helps develop and standardise methodologies to be used for routine assessment, and consequently selection; maximising heritability readily translates to increased genetic gain (Bernardo, 2010; Acquaah, 2012). Thus, the objectives of this study were to determine broad-sense heritability (or repeatability) for softness of cooked cassava roots, and to quantify the relationship between penetrometer and consumer testing methods for phenotyping softness of cassava roots.

\section{MATERIALS AND METHODS}

Genetic materials. In order to examine the extent of heritability (repeatability) of root softness in cassava, we assembled 285 genotypes from two sources in Uganda, namely smallholder farmers resident in northern, western and west Nile region, and from the cassava breeding populations developed by National Crops Resources Research Institute (NaCRRI). The names of genotypes cultivated by smallholder farmers were recorded during the end-user cassava trait preference survey.

The study plan for this survey and consent forms were reviewed by the Institutional Review Board (IRB) of Cornell University and approved (IRB ID 1502005316). After the survey, we collected stem cuttings from each of the named varieties at the sub-county level, forming a total of 76 variety names. The list of the variety names can be accessed at ftp:// ftp.cassavabase.org/manuscripts/ Iragaba et al 2019 quality/Phenotype infos/ (in a file named: "Farmer varieties included in the study to evaluate genetic variability of softness of cooked cassava roots.txt"). The stem cuttings were collected from three different plants for each of the 76 varieties. We treated each plant as a unique genotype, because earlier studies had shown that not all varieties with the same name are genetically identical (Rabbi et al., 2015). In total, we obtained 223 genotypes from the farmers' fields.

To complement the farmer varieties, we selected 78 genotypes sampled from a diversity panel of 635 genotypes that were generated by crossing germplasm from International Institute for Tropical Agriculture (IITA) with that sourced from the International Center for Tropical Agriculture (CIAT) (Kayondo et al., 2018).

To sample the extent of phenotypic variation for two critical agronomic traits, harvest index (HI) and dry matter content (DMC), we constructed a scatter plot (HI against DMC) and divided the resultant scatter plot into four quadrants. We selected a nearly equivalent number ranging from 19 to 20 genotypes from each quadrant and thus, identified the representative 78 genotypes (Fig. 1). The lists 


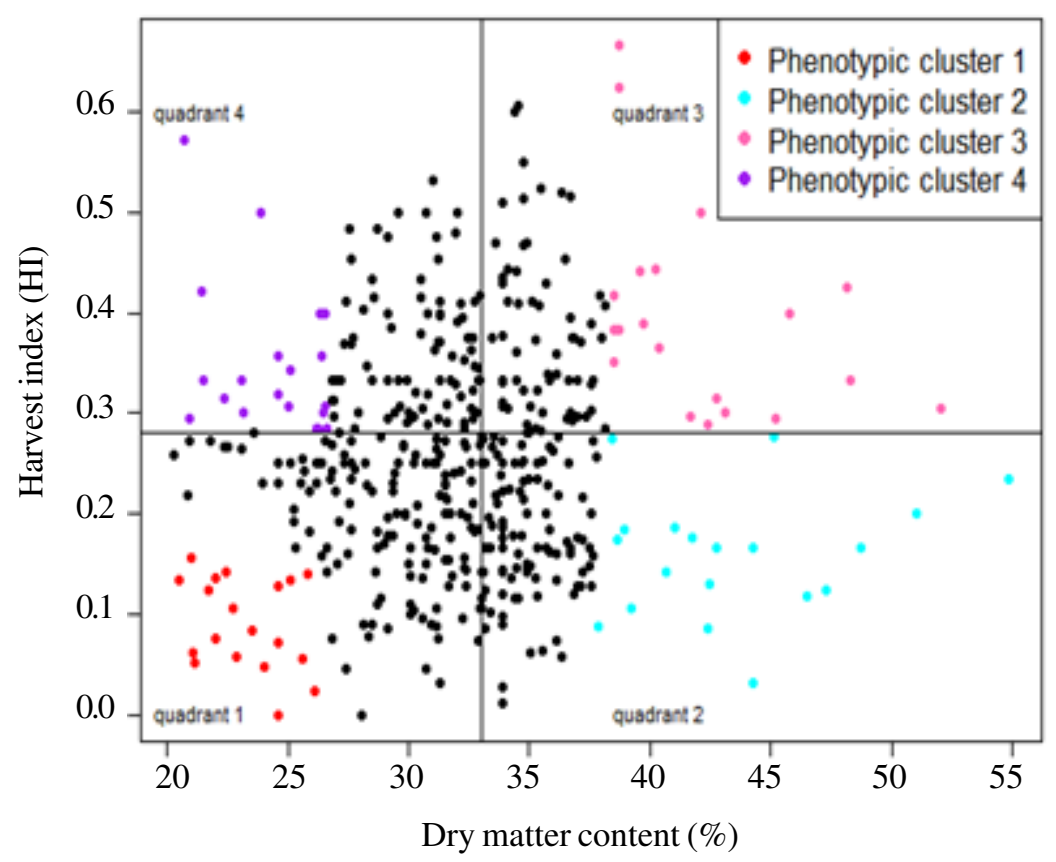

Figure 1. Scatter plot of harvest index (HI) against dry matter content (DMC) for 635 genotypes from a cassava diversity panel maintained by National Crops Resources Research Institute (NaCRRI), with the 78 genotypes (coloured points) selected to sample the maximal phenotypic diversity.

of the selected genotypes are stored in CassavaBase: ftp://ftp.cassavabase.org/ manuscripts/Iragaba et al 2019 quality/ (in a file named: "The 78 genotypes were selected from a total of 635 genotypes that comprise the diversity panel maintained at National Crops Resources Research Institute.txt")

We then ascertained whether the 78 genotypes selected for maximum variation in HI and DMC represented the extent of genotypic diversity in the panel. To achieve this, we conducted a Principal Component Analysis (PCA), with the prcomp function of the stats package in R (R Core Team, 2015), using 61,297 single-nucleotide polymorphism (SNP) markers that were previously scored on the 635 genotypes (Kayondo et al., 2018). Then, $K$-means clustering was performed with the kmeans function of the stats package in $\mathrm{R}$, to divide the 635 genotypes into four genetic clusters. This was followed by intersecting the PCA and $K$-means clustering results to determine which of the four clusters each of the 78 genotypes belonged (Fig. 2). Taken together, these analyses confirmed that the 78 genotypes selected for their phenotypic diversity also captured the major patterns of genotypic diversity present in the entire panel (Fig. 3). However, at the time of collection of planting materials, we obtained 62 genotypes because they were the only ones with sufficient cuttings.

Experimental design. During the second rains of 2015 , the 285 genotypes (223 collected from farmers and 62 from breeding programme) were established in the field in an augmented incomplete block design in two sites: Adravu village, Manibe sub-county, Arua district (northwestern Uganda), and Namaswata village, Kassanda sub-county, Mubende district (central Uganda). The altitude (1200 - 1400 masl), average annual rainfall $(1250 \mathrm{~mm})$, and average temperature $\left(22^{\circ} \mathrm{C}\right)$ of Arua are higher than those of Mubende (Arua District Local Government, 2012; Mubende District Local Government, 2013). Adravu village has an average 


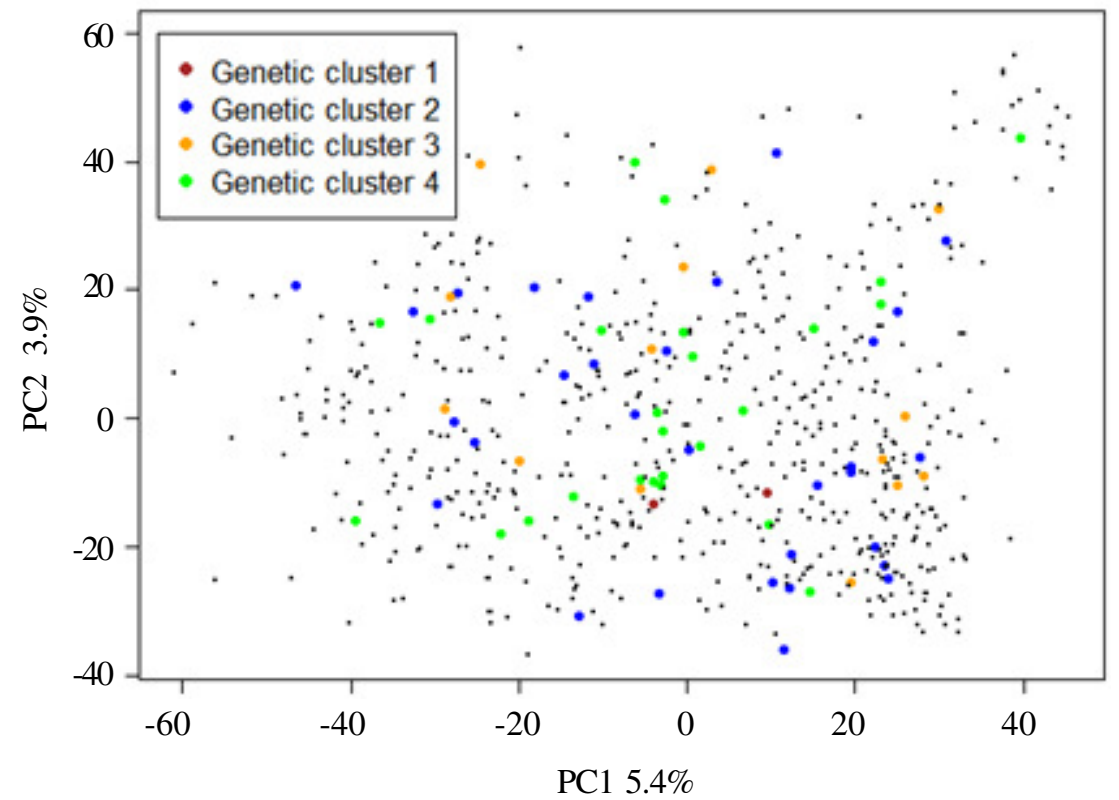

Figure 2. Principal Component Analysis (PCA) plot of PC1 and PC2 of the genetic diversity in the National Crops Resources Research Institute (NaCRRI) population, with only the 78 selected genotypes colored and labeled according to which of the four $K$-means clusters each genotype belongs. The PCA is based on 61,297 single-nucleotide polymorphism markers scored on 635 cassava genotypes.

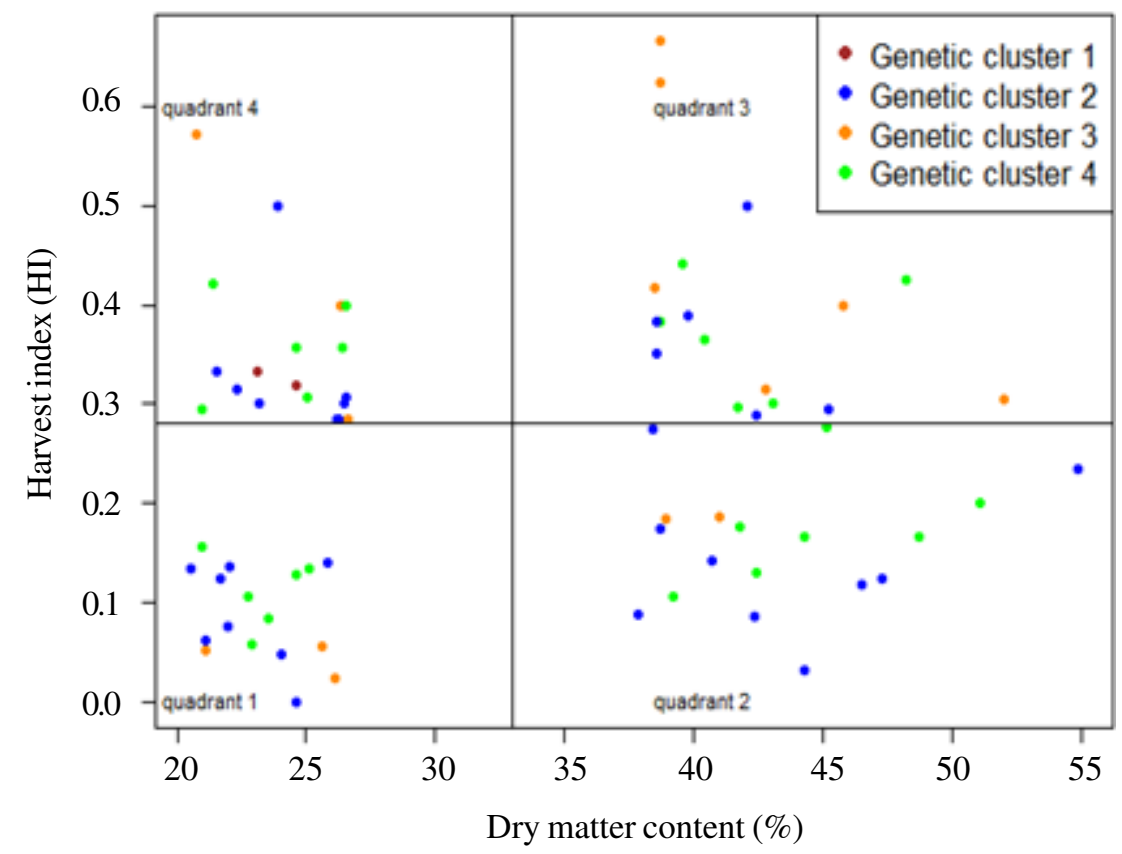

Figure 3. Scatter plot of harvest index (HI) against dry matter content (DMC) for the 78 selected genotypes labeled according to their $K$-means cluster. 
temperature of $24.0^{\circ} \mathrm{C}$ and annual rainfall of $1385 \mathrm{~mm}$; whereas Namaswata village has an average temperature of $21.5^{\circ} \mathrm{C}$ and annual rainfall of $970 \mathrm{~mm}$ (Fick and Hijmans, 2017). These two field sites provide contrasting environments for the phenotypic evaluation of the softness phenotype. Arua had 14 incomplete blocks, with 25 plots per incomplete block, while Mubende had 12 incomplete blocks with 30 plots per incomplete block. Each incomplete block was augmented by the addition of three check genotypes namely, NAROCASS 1, NASE 14, and TME 14 grown at the two sites. In addition, NASE 4 was used as a local check in Arua, while UGL15228 was used as the local check in Mubende. Three of these genotypes (NAROCASS 1, NASE 14 and NASE 4) have been officially released in Uganda. Within each incomplete block, the order of entries was randomised.

Experimental units were one-row plots, measuring $5 \mathrm{~m}$ in length; each plot was represented by five plants that were evenly spaced and had a between row spacing of $1 \mathrm{~m}$. Each block was separated from the other by an alley of $2 \mathrm{~m}$ width.

At maturity (12 months after planting), all plants were uprooted and their roots bulked per plot. Subsequently, four to six intact, uniformly sized roots were randomly sampled from each plot, and appropriately labeled as per the field layout available at www.cassavabase.org. The sampled roots were immediately washed with tap water to remove soil debris, followed by air drying of residual moisture from the root surface for 15-30 min. To prolong the shelf life of cassava roots prior to softness assessment, we waxed the roots on the day of harvest (Lebot, 2009). The roots were waxed by immersing them for five seconds in pre-melted food-grade wax maintained at $140-160{ }^{\circ} \mathrm{C}$, and thereafter, cooled to air temperature outside in the field from where the cassava was harvested.

Root samples could not be obtained for all 285 genotypes across the two locations because plants for some genotypes did not survive up to the time of harvest. Accordingly, data were collected from 236 and 237 genotypes from Arua and Mubende, respectively. This resulted into a total of 268 genotypes that had phenotypic data from at least one of the two environments.

Penetrometer assessment. The waxed roots from the two field locations were stored in a $-80^{\circ} \mathrm{C}$ freezer to avoid deterioration prior to softness evaluation. Freezing was done to ensure long preservation (more than one month), because waxing can only preserve roots for about one month (Lebot, 2009). In a pilot experiment that we conducted earlier with ten genotypes, root softness for frozen root samples over a duration of 30 days was strongly correlated $\left(r^{2}=0.76, P\right.$-value $=$ 0.0009 ) with softness from fresh roots. This provided confidence in the freezing process adopted to handle the relatively high number of samples analysed in this study.

Accordingly, samples for a given block were removed from the freezer and thawed at room temperature (approximately $23^{\circ} \mathrm{C}$ ). After thawing, two roots per plot (genotype) were peeled and sliced into $3 \mathrm{~cm}$ sections using a knife and ruler. For each genotype, four sections were randomly selected from the sliced sections and loosely wrapped in perforated aluminum foil. The selected sections were cooked in a water bath set at a constant near boiling temperature of $90^{\circ} \mathrm{C}$, and softness assessment done at four time points: 15, 30, 45 and $60 \mathrm{~min}$. This was done by removing a root section at each defined time point, and softness assessment done. Thus, each root was assessed for softness at four cooking time points: $15,30,45$ and $60 \mathrm{~min}$.

Softness was defined as the maximum force used to penetrate the root section using the penetrometer. Thus, at each time point, the $7.9 \mathrm{~mm}$ diameter tip of a digital penetrometer (Model number: FHT-1122, Vetus Industrial Company Limited, Hefei, China) was pushed to a depth of $1 \mathrm{~cm}$ into 
each cooked root section. This was done at three different positions of the sectioned root i.e., three technical measurements taken per root section. Hence, we obtained three observations for each time point, per genotype per site, a dataset appropriate for quantifying heritability for root softness in cassava.

Consumer acceptability testing in Kibaale. To corroborate the quantitative softness data, particularly the softness assessment by penetrometer, we conducted on-site consumer testing in Kibaale district, one of the districts with high consumption of cassava (Nakabonge et al., 2017). The study plan for consumer testing and consent forms were reviewed by IRB of Cornell University and approved (IRB ID 1809008241). Accordingly, root softness for six commonly grown varieties in Kibaale (Bukalasa, Gwalanda, Kyawada, NAROCASS1, NAROCASS 2, and Matooke) were evaluated using both the consumer testing method, by 135 consumers, and by the penetrometer method. For validity of results from consumer acceptability testing, it is recommended to involve at least 112 consumers (Hough et al., 2006); thus in our study the aim was to work with a minimum of 112 consumers.

The six varieties chosen represented the greatest diversity in softness for commonly grown varieties: Bukalasa and Matooke were classified as "soft", while Gwalanda and Kyawada were described as "hard" varieties by farmers, during the survey held in 2015 . We also included two recently released varieties from the NaCRRI breeding programme, namely NAROCASS 1 ("soft") and NAROCASS 2 ("hard"). The consumers in this study were men and women who had historically grown and consumed cassava, and thus were considered to be experienced to provide reliable information (Safo-kantanka and Owusu-nipah, 1992; Bechoff et al., 2018b).

Before starting the consumer testing activity, we read a consent statement to the entire group of participants to seek their approval to participate in the study, explained the purpose of the study, methods to be used, and let them know that their participation was voluntary and that they were free to withdraw at any time during the study. Consumers who participated in the study were disaggregated by age and sex. Of the total number of consumers, $51.5 \%$ were women (18-30 age group that constituted $25.0 \%$, and $31-70$ age group that constituted $26.5 \%$ ), and $48.5 \%$ were men (18-30 age group that constituted $19.4 \%$, and $31-70$ age group that constituted $29.1 \%$ ).

Freshly uprooted cassava roots of the six varieties, harvested at 12 months, were peeled and each cut into $3 \mathrm{~cm}$ sections to generate at least 140 root sections per variety. These root sections for each genotype were washed twice in tap water to remove debris and adhering soil particles. Thereafter, the roots were wrapped in banana (Musa spp.) leaves, as routinely done when preparing boiled cassava roots in the study area. The six wraps, each representing a given genotype, were carefully placed into a single saucepan with tap water at room temperature (approximately $23{ }^{\circ} \mathrm{C}$ ). The top of the saucepan was fully covered with layers of banana leaves and another saucepan was used as a lid; this was followed by cooking of roots over wood fire for 50 $\min$.

After the cassava roots had cooked for 50 min, the roots were withdrawn from the wood fire and assessed for softness. Of the 140 root sections cooked per variety, 110 were used for assessing consumer acceptability by selected consumers, while the remaining 30 were used for measuring softness with the penetrometer. For testing of consumer acceptability, each of the 110 root sections was cut into halves, resulting in a total of 220 root sections for assessment per variety. At the time of consumer testing, each participant was served one root section per variety to score softness, using an ordinal 1-5 scale modified from ISO (1994), where 1 = extremely soft, 
$2=$ soft, $3=$ neither soft nor hard, $4=$ hard, and $5=$ extremely hard. The softness evaluation was based on the disintegration ability of the cooked roots in the mouth of the consumers (Padonou et al., 2005). Each of the six varieties was evaluated once by each of the 135 consumers, thus 135 root sections were used. The remaining unused root sections were discarded at the end of the consumer testing process.

Penetrometer-based root softness assessment (after cooking roots for $50 \mathrm{~min}$ ) was done on each variety at six post-cooking time points: $0,15,30,45,60$ and 75 min after withdrawing the roots. The first $(0 \mathrm{~min})$ and last $(75 \mathrm{~min})$ time points corresponded to the initiation and completion of consumer testing in Kibaale, respectively. Measuring softness at the six post-cooking time points throughout the entire period of consumer evaluation allowed us to better account for the influence of cooling on root softness. At each time point, five cooked root sections per variety were randomly sampled from the bulk (in saucepan) and assessed for softness using the penetrometer, as described earlier. Assessments were done on two different sides of each section, and thereafter, the section was discarded. In total, 360 penetrometer measurements were recorded.

\section{Statistical analyses}

Softness quantitative data. In order to determine heritability of root softness, we jointly analysed softness data generated from Arua and Mubende trials. Initially, we processed each cooking time point $(15,30$, 45 and $60 \mathrm{~min}$ ) separately, and thus generated four datasets for root softness. For each dataset, the Box-Cox power transformation (Box and Cox, 1964) was conducted to identify the optimal transformation procedure that best corrected for unequal variances and nonnormality of error terms. This analysis was conducted in the MASS package in R (R Core Team, 2015) by fitting a linear model where genotype, environment, incomplete block nested within environment, and plot grid row nested within environment, were fitted as fixed effects. The softness data for 30, 45, and 60 min time points did not need transformation (optimal convenient lambda $=1$ ), whereas the square root transformation (optimal convenient lambda $=0.5$ ) was needed for the softness data collected at $15 \mathrm{~min}$.

We fitted a mixed linear model for softness at each time point, to identify and remove significant outliers from the raw data in ASReml-R version 3.0 (Gilmour et al., 2009). The full model used to analyse data collected at each time point had check lines as fixed effects and all other terms from the simple linear model described above, as random effects. The Studentised deleted residuals (Neter et al., 1996) were examined to identify and remove significant outliers.

After outliers were removed, an iterative mixed linear model fitting procedure of the full model was conducted in ASReml-R version 3.0 (Gilmour et al., 2009). Likelihood ratio tests were conducted to remove all random effect terms from the model that were not significant at $\alpha=0.05$ (Littell et al., 2006) to generate a final, best fitted model for softness at each time point that enabled generation of best linear unbiased predictors (BLUPs) for each genotype.

For softness at each time point, the variance components from the final model were used to estimate broad-sense heritability (or repeatability) on an entry-mean basis (Holland et al., 2003). Standard errors of the heritability estimates were approximated with the delta method (Holland et al., 2003). Pearson's correlation coefficients $(r)$ were computed and used to assess the relationship between softness BLUPs for each pair of time points. This was done using the cor function of the stats package in R (R Core Team, 2015). The significance of the Pearson's correlation coefficient was declared at $\alpha=0.05$ with the cor.test function of the stats package. To represent the true directionality of the relationship between softness BLUPs, the transformed BLUPs at the 15 min time point 
were back-transformed prior to conducting the correlation analysis.

Analysis of consumer data. We used a linear model to analyse the consumer evaluation scores. The Box-Cox procedure (Box and Cox, 1964) was implemented by fitting a linear model, where the fixed effects were variety, sex, and age, with consumer evaluation scores as the dependent variable in the MASS package in $\mathrm{R}$. The convenient Lambda of 1.0 was obtained and thus, data were not transformed. Data were screened for outliers in ASReml-R version 3.0 (Gilmour et al., 2009), by examining the Studentised deleted residuals (Neter et al., 1996) obtained from a linear model fitted with variety, sex, and age as fixed effects. The resultant data were then used to refit the same model in ASReml-R, to conduct an analysis of variance (ANOVA) and estimate the best linear unbiased estimator (BLUE) for each variety. The Tukey-Kramer honest significance (HSD) test $(P$-value $<0.05)$ was used to determine if varieties were significantly different from each other.

A linear model was also used to analyse penetrometer data that were collected as a comparison to the consumer evaluation scores. For the penetrometer data across all six postcooking time points $(0,15,30,45,60$ and 75 $\min$ ), a series of linear models with variety, time point, and their interaction were fitted as fixed effects to find the most appropriate transformation; the log transformation was made for all six time points. We screened for outliers as described earlier. We estimated a BLUE for each variety across all six time points (used for correlation analysis) and at each single time point (used for time series plot). To evaluate whether varieties were significantly different from each other across all six time points, the Tukey-Kramer HSD test $(P$-value $<0.05)$ was used. The relationship between BLUEs of softness from consumer testing and the penetrometer (across all six time points) was assessed as described earlier. The $\log$ transformed penetrometer BLUEs were back-transformed prior to conducting the correlation analysis.

\section{RESULTS}

Heritability estimates. As for the cassava roots cooked from 15 to $60 \mathrm{~min}$, there was a trend of reduced force $(\mathrm{N})$ required to penetrate the roots (Table 1). The highest average amount of force $(3.33 \mathrm{~N})$ required to penetrate the roots was recorded after cooking for 15 min, with genotype UG140335 requiring the highest amount of force $(3.76 \mathrm{~N})$; while

TABLE 1. Best linear unbiased predictors and heritability estimates of cassava root softness following four different cooking durations

\begin{tabular}{|c|c|c|c|c|c|c|}
\hline \multirow[t]{2}{*}{ Cooking time $(\mathrm{min})^{\mathrm{a}}$} & \multirow{2}{*}{$\begin{array}{l}\text { Number of } \\
\text { cassava } \\
\text { genotypes }^{b}\end{array}$} & \multicolumn{3}{|c|}{ BLUPs $^{c}$} & \multicolumn{2}{|c|}{ Broad-sense heritability } \\
\hline & & Mean $(\mathrm{N})$ & $\mathrm{SD}^{\mathrm{d}}(\mathrm{N})$ & Range (N) & Estimate & $\mathrm{SE}^{\mathrm{e}}$ \\
\hline 15 & 268 & 3.33 & 0.155 & $2.94-3.76$ & 0.22 & 0.087 \\
\hline 30 & 268 & 2.78 & 0.154 & $2.45-3.27$ & 0.28 & 0.081 \\
\hline 45 & 267 & 2.47 & 0.205 & $1.94-3.21$ & 0.37 & 0.076 \\
\hline 60 & 267 & 2.20 & 0.096 & $1.89-2.49$ & 0.17 & 0.092 \\
\hline
\end{tabular}

aData based on analysis across two locations: Arua (west Nile region) and Mubende (central region); Back-transformed BLUPs are reported for the $15 \mathrm{~min}$ time point; ${ }^{\mathrm{b}}$ Only 267 genotypes were evaluated at the 45 and 60 min cooking times, because one of the genotypes did not have enough roots for phenotypic evaluation; ${ }^{\mathrm{c} B L U P s}$, best linear unbiased predictors; ${ }^{\mathrm{d}} \mathrm{SD}$, standard deviation of the BLUPs; and ${ }^{e} S E$, standard error of heritabilities 
the lowest average force $(2.20 \mathrm{~N})$ was recorded after the roots cooked for $60 \mathrm{~min}$ with genotype UG142019 requiring the least amount of force $(1.89 \mathrm{~N})$. The BLUPs for root softness of all the genotypes are stored in CassavaBase at ftp://ftp.cassavabase.org/ manuscripts/Iragaba et al 2019 quality/ Phenotype_infos/ (in a file named: "BLUPs softness manuscript.txt"). We observed the widest range of variation $(1.94-3.21 \mathrm{~N})$ for root softness at the 45 min cooking time point; while the narrowest variation $(1.89-2.49 \mathrm{~N})$ was observed after cooking for $60 \mathrm{~min}$ (Table $1)$.

Broad-sense heritability (or repeatability) was estimated for root softness at each of the four cooking time points; and overall moderate heritability estimates were observed (Table 1). Heritability estimates increased from 0.22 (after cooking for $15 \mathrm{~min}$ ) to a maximum of 0.37 (after cooking for $45 \mathrm{~min}$ ); and declined to 0.17 for roots cooked for $60 \mathrm{~min}$.

Statistically significant $(P$-value $<0.0001)$ correlations were detected between all pairwise comparisons of root softness (Fig.
4). All correlations were positive, with an observed range of moderate $(r=0.45)$ to strong $(r=0.73)$ correlation coefficient values (Fig. 4). The strongest correlation was detected between trait BLUP values for the $30 \mathrm{~min}$ and 45 min cooking times, whereas the correlation of trait BLUP values between the $15 \mathrm{~min}$ and 60 min cooking times was the weakest. In general, correlations were strongest for trait BLUPs between cooking times separated by only $15 \mathrm{~min}$, congruent with expectations.

\section{Consumer testing versus penetrometer} methods. A total of 135 consumers from Kibaale district (western Uganda) participated in consumer testing of six cassava varieties, namely Bukalasa, Gwalanda, Kyawada, NAROCASS 1, NAROCASS 2, and Matooke. Unlike in the above-mentioned results where softness was assessed at four time points, for this study, softness was assessed at six postcooking time points $(0,15,30,45,60$ and 75 $\mathrm{min})$. Results revealed that root softness varied significantly $(P$-value $<0.0001)$ between varieties (Table 2), while sex and age of the

\section{$60 \mathrm{~min}$}

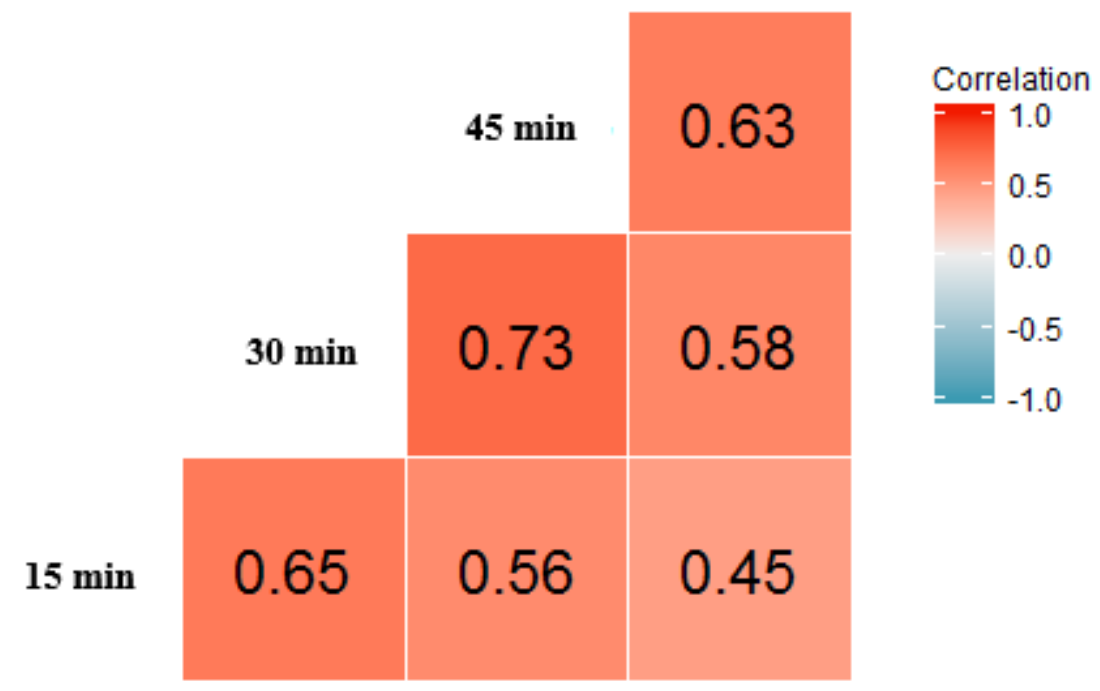

Figure 4. Pearson correlation coefficients $(r)$ for best linear unbiased predictors of cassava root softness measured by a penetrometer at the end of four cooking time points: 15, 30, 45 and $60 \mathrm{~min}$. All correlations were significant at $\alpha=0.05$. 
consumers had no significant effect ( $P$-value $>0.05)$. Given that consumer testing occurred over a period of $75 \mathrm{~min}$, the penetrometer was used to collect measurements on cooked roots at six post-cooking time points $(0,15,30,45$, 60 and $75 \mathrm{~min}$ ). This provision allowed for taking records of cooling effects on root

TABLE 2. F-values for fixed sources of variation from an analysis of variance for consumer scores of softness for roots from six cassava varieties that were cooked for 50 minutes

\begin{tabular}{lrc}
\hline Source & DF & F-value \\
\hline Variety & 5 & $403.34^{* * * *}$ \\
Sex & 1 & $0.29^{\mathrm{NS}}$ \\
Age & 1 & $0.75^{\mathrm{NS}}$ \\
Residual & 796 &
\end{tabular}

NS, Not significant at the $<0.05$ level.

${ }^{* * * *}$ Significant at the $<0.0001$ level softness; uniquely, this provides for a fair comparison of penetrometer and consumer testing (Fig. 5). We found statistically significant differences $(P$-value $<0.0001)$ for variety, time point, and their interaction (Table 3). Indicative of high concordance between softness assessment methods, a strong

TABLE 3. F-values for fixed sources of variation from an analysis of variance for penetrometer measurements of softness for roots from six cassava varieties

\begin{tabular}{lrr}
\hline Source & DF & F-value \\
\hline Variety & 5 & $228^{* * * *}$ \\
Time point ${ }^{\mathrm{a}}$ & 5 & $453^{* * * *}$ \\
Variety*Time point $^{*}$ & 25 & $34^{* * * *}$ \\
Residual & 143 & \\
\hline
\end{tabular}

**** Significant at the $<0.0001$ level. ${ }^{\text {a Roots were }}$ evaluated at six post-cooking time points $(0,15$, $30,45,60$ and $75 \mathrm{~min}$ ) after cooking for 50 minutes

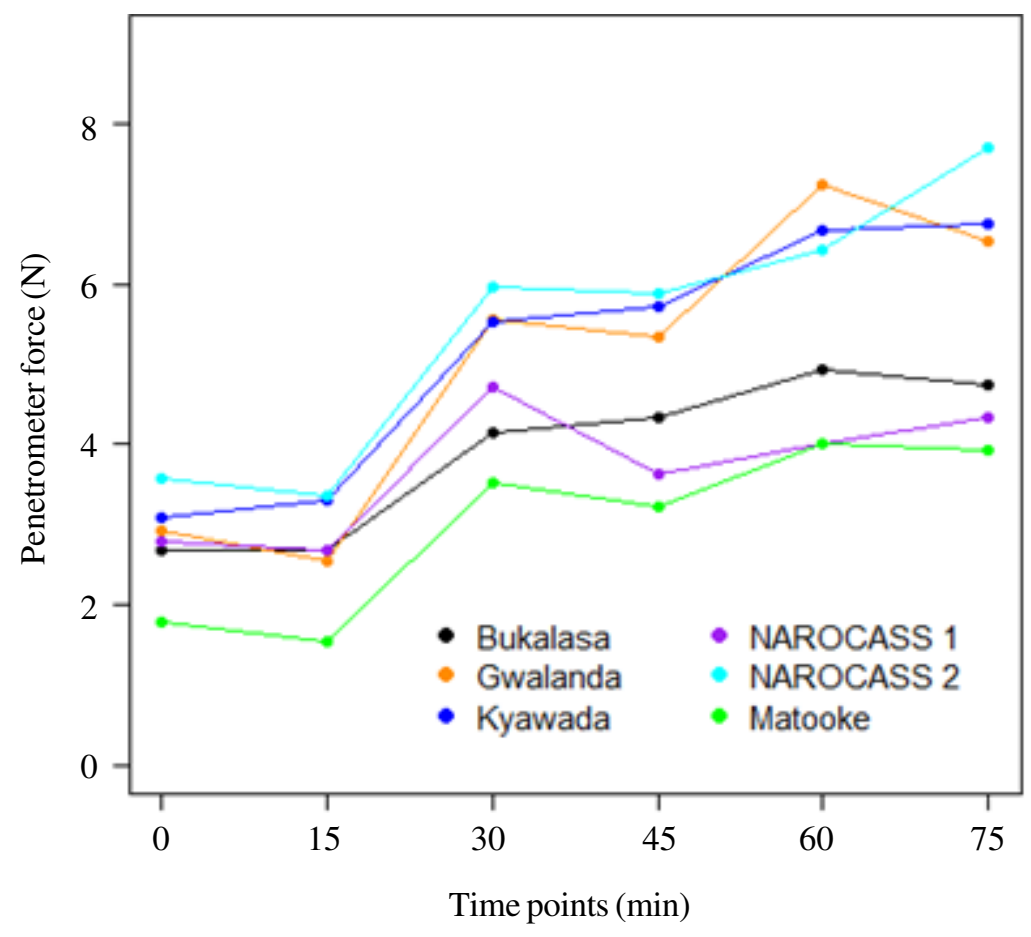

Figure 5. Time series of back-transformed BLUEs for root softness measured by the penetrometer at six post-cooking time points for six cassava genotypes. 
agreement $\left(r^{2}=0.91\right)$ was detected between the BLUEs of penetrometer root softness and consumer testing (Fig. 6).

The Tukey-Kramer HSD test grouped the varieties from consumer testing and penetrometer methods in similar sub-groups (Fig. 7). In both methods, Matooke, Bukalasa and NAROCASS 1 had the lowest values (softer); whereas Kyawada, Gwalanda and NAROCASS 2 had the highest values (harder). The sub-groups of the varieties were in concordance with the prior consumer classification regarding the level of softness.

\section{DISCUSSION}

The highest broad-sense heritability (0.37) was observed among cassava genotypes from Arua and Mubende after cooking for $45 \mathrm{~min}$ (Table 1), implying that selecting for root softness at 45 min after cooking would maximise genetic gain for softness. Similarly, it was at $45 \mathrm{~min}$ that we obtained the highest standard deviation for the estimates of BLUPs, indicating a considerable amount of genetic variation, and thus scope for breeding for root softness in cassava. In part, the relatively lower broadsense heritabilities observed at 15 and $60 \mathrm{~min}$ could be attributed to the fact that most varieties had not yet cooked at $15 \mathrm{~min}$, or had over cooked at $60 \mathrm{~min}$. Previous studies, though limited by number of clones (less than 30 clones), have observed phenotypic variability for softness of cooked cassava roots (Ngeve, 2003; Beleia et al., 2004a; Padonou et al., 2005).

In the present study, the reported broadsense heritability estimates provide an indication of the proportion of observed phenotypic variance of a population that is due to genetic effects. In theory, this indicates how much genetic gain can be achieved by the breeder (Holland et al., 2003; Acquaah, 2012). Notably, none of the previous studies quantified heritability for softness, an important aspect in guiding selection of genotypes with

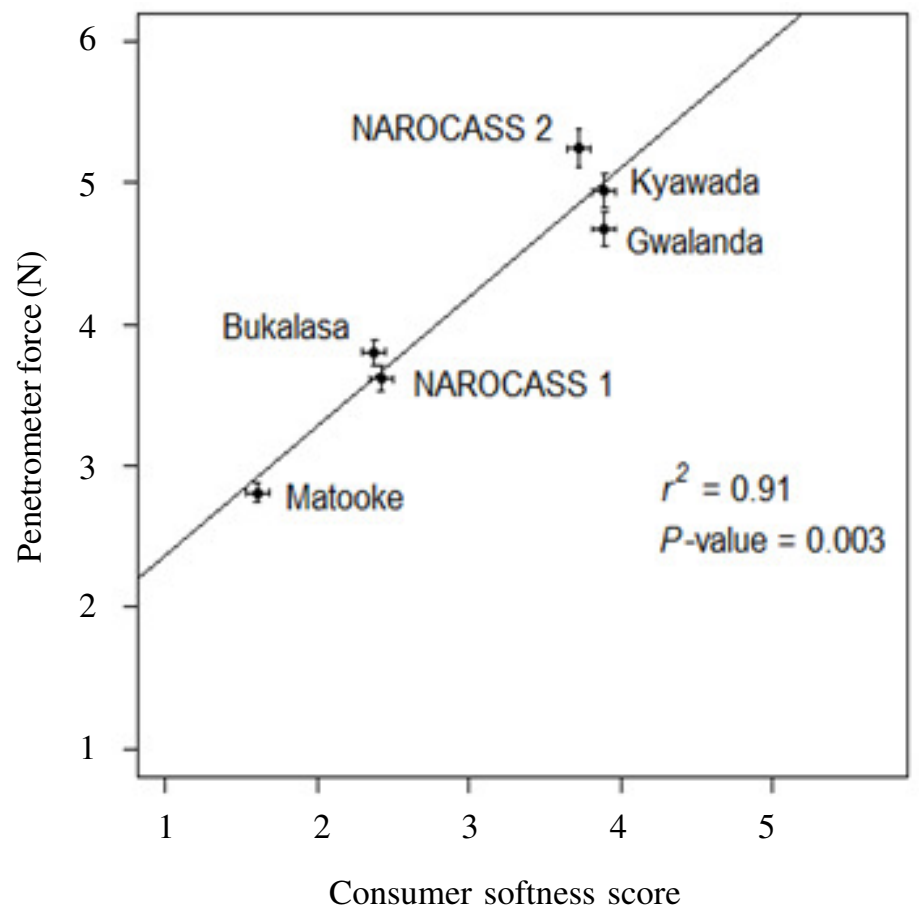

Figure 6. The relationship between BLUEs of penetrometer measurements and consumer scores of softness for cassava roots of six genotypes that were cooked for 50 minutes. 

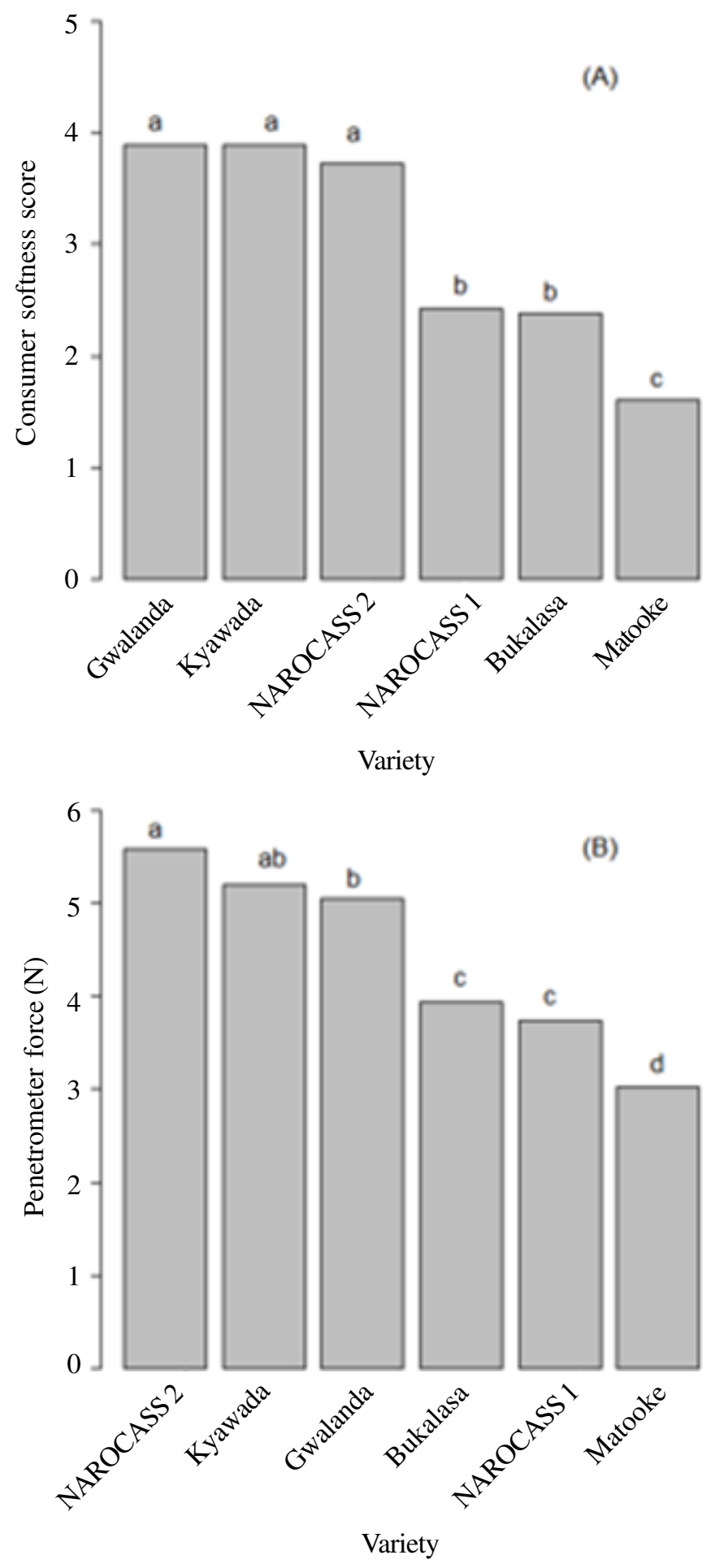

Figure 7. (A) Bar plot showing Tukey-Kramer HSD means separation of softness for six cassava genotypes based on consumer testing evaluation; (B) the penetrometer method. Means followed by the same letter are not significantly different at $\alpha=0.05$. 
favourable attributes by breeders during new variety development process. Results in the present study provide the first insights in determining the broad-sense heritability for softness.

The observed differences in softness among genotypes (Table 1 and Fig. 7) could be attributed to the differences in the amount of pectin and/or intercellular cell-wall adhesions (Eggleston and Asiedu, 1994; Favaro et al., 2008; Maieves et al., 2012). Eggleston and Asiedu (1994) reported that the cell-walls of mealy cassava varieties were less cohesive than those of non-mealy varieties. Favaro et al. (2008) examined the effect of thermal treatment on softening of cassava roots, and found that longer cooking times softened tissue due to reduction in intercellular adhesive strength. Furthermore, previous studies on the softness of cooked cassava roots have indicated that age of a genotype at harvest, season and soil type affect the level of softness (Ngeve, 2003; Padonou et al., 2005).

In the present study, a general trend of reduction in average force was required to penetrate the roots from $15 \mathrm{~min}$ to $60 \mathrm{~min}$ cooking times (Table 1). This trend conforms to what is expected since prolonged cooking should lead to softening of the roots. Several studies have reported that prolonged cooking time leads to softening of cassava roots (Lorenzi, 1994; Beleia et al., 2004b, 2006).

We quantified the relationship between the two methods of assessment of root softness; the penetrometer and consumer-based evaluations. We observed a strong correlation $\left(r^{2}=0.91 ; P\right.$-value $\left.=0.003\right)$ between both methods implying that the penetrometer can be reliably used to estimate softness of cooked cassava roots as evaluated by consumers. This finding compares well with the correlation of 0.75 reported by Padonou et al. (2005) in determining the relationship between sensory evaluation and penetration test by an instrument in cassava.

Ideally, consumer testing would be the best direct method for evaluation of softness (Safo- kantanka and Owusu-nipah, 1992; Padonou et al., 2005); however, it is ineffective for assessing variability for a large number of genotypes that are often encountered in early evaluation stages. Thus, the strong correlation between penetrometer and consumer testing results justify the use of the penetrometer as an indirect method to measure softness of cooked cassava roots. The advantage of the penetrometer over consumer testing would be its efficiency when dealing with large sample sizes. Furthermore, it avoids subjectivity that is commonplace when using non-expert consumer evaluation panels.

\section{CONCLUSION}

This study has provided the first insights into heritability estimates for softness of cooked cassava roots, for which we observed moderate heritabilities $\left(H^{2}=0.37\right)$ at $45 \mathrm{~min}$ cooking time. Evaluating genotypes at this time point will, within limits, increase selection efficiency, leading to overall increase in genetic gain. Secondly, there is a high correlation $\left(r^{2}\right.$ $=0.91$ ) between penetrometer and consumer testing results for root softness. Thus, we recommend the use of the penetrometer method as a high-throughput phenotyping tool for softness of cooked cassava roots.

\section{ACKNOWLEDGEMENT}

This research was undertaken as part of Roots, Tubers and Bananas (RTB) research, and funded by, the CGIAR Research Programme on RTB and supported by CGIAR Trust Fund contributors. Additional funds were provided by the Next Generation Cassava Breeding Project through funds from the Bill and Melinda Gates Foundation (Project No. OPP1048542) and the Department for International Development of the United Kingdom (UKaid) (Project No. OPP1048542). We thank the technical staff of National Crops Resources Research Institute (NaCRRI) Root Crops Programme, who assisted with field trial 
establishment, maintenance, and data collection both in the field and laboratory. We also acknowledge the technical guidance from RTBfoods project staff. We give special thanks to Guillaume Bauchet for assistance in data curation.

\section{REFERENCES}

Acquaah, G. 2012. Principles of Plant Genetics and Breeding. Second Edi. John Wiley and Sons, Inc., West Sussex, PO19 8SQ, UK. 740pp.

Alene, A.D., Khataza, R., Chibwana, C., Ntawuruhunga, P. and Moyo, C. 2013. Economic impacts of cassava research and extension in Malawi and Zambia. Development and Agricultural Economics 5(11):457-469. doi: 10.5897/JDAE 2013.0496.

Arua District Local Government. 2012. Arua District Local Government Statistical Abstract. https://www.ubos.org/online files/uploads/ubos/Arua.pdf. Accessed 25 March 2019

Bechoff, A., Tomlins, K., Fliedel, G., Becerra, L.A. Westby, A., Hershey, C. and Dufour, D. 2018a. Cassava traits and end-user preference: Relating traits to consumer liking, sensory perception, and genetics. Critical Reviews in Food Science and Nutrition 58(4):547-567. doi: 10.1080/ 10408398.2016.1202888.

Bechoff, A., Chijioke, U., Westby, A. and Tomlins, K.I. 2018b. Yellow is good for you: Consumer perception and acceptability of fortified and biofortified cassava products. PLoS One 13(9):1-23. doi: 10.1371/journal.pone.0203421.

Beleia, A., Butarelo, S.S. and Silva, R.S.F. 2006. Modeling of starch gelatinization during cooking of cassava (Manihot esculenta Crantz). LWT - Food Science and Technology 39(4): 399-404. doi: 10.1016/ j.lwt.2005.02.021.

Beleia, A., Prudencio-Ferreira, S.H., Yamashita, F., Sakamoto, T.M. and Ito,
L. 2004a. Sensory and instrumental texture analysis of cassava (Manihot esculenta Crantz) roots. Journal of Texture Studies 35: 542-553.

Beleia, A., Yamashita, F., De Moraes, S.R., Da Silveira, C.A. and Miranda, L.A. 2004b. Textural changes during cooking of cassava (Manihot esculenta Crantz) roots. Journal of the Science of Food and Agriculture 84(14): 1975-1978. doi: 10.1002/jsfa.1917.

Bernardo, R. 2010. Breeding for quantitative traits in plants. Second Edition. Stemma Press, Woodbury, MN., USA. 390pp.

Box, G.E.P., and Cox, D.R. 1964. An Analysis of Transformations. Royal Statistical Society. Series B (Methodological) 26(2): 211-252.

Ceballos, H., Iglesias, C.A., Perez, J.C. and Dixon, A.G.O. 2004. Cassava breeding: Opportunities and challenges: Plant Molecular Biology 56:503-516.

Chiwona-Karltun, L., Nyirenda, D., Mwansa, C.N., Kongor, J.E., Brimer, L., Haggblade, S. and Afoakwa, E.O. 2015. Farmer preference, utilization, and biochemical composition of improved Cassava (Manihot esculenta Crantz) varieties in Southeastern Africa. Economic Botany 69(1): 42-56. doi: 10.1007/s12231-0159298-7.

Eggleston, G. and Asiedu, R. 1994. Effects of boiling on the texture of cassava clones: A comparison of compressive strength, intercellular adhesion and physico-chemical composition of the tuberous roots. Tropical Science 34: 259-273.

FAO. 2013. Save and grow cassava: A guide to Sustainable Production Intestification. Rome, Italy. 129pp. http://www.fao.org/ 3/a-i3278e.pdf. Accessed 20 March 2019.

FAO and IFAD. 2000. The world Cassava Economy: Facts, Trends and Outlook. Viale delle Terme di Caracalla, 00100 Rome, Italy. 46pp.

Favaro, P.S., Beleia, A., da Silva Fonseca Junior, N. and Waldron, W.K. 2008. The roles of cell wall polymers and intracellular 
components in the thermal softening of cassava roots. Food Chemistry 108:220227. doi: 10.1016/j.foodchem.2007.10. 070 .

Fick, S. and Hijmans, R. 2017. Worldclim 2: New $1-\mathrm{km}$ spatial resolution climate surfaces for global land areas. International Journal of Climatology. http://worldclim. org/version2.

Gilmour, A.R., Gogel, B.J., Cullis, B.R. and Thompson, R. 2009. ASReml user guide release 3.0. VSN International Ltd, Hemel Hempstead, HPI IES, UK. 372pp.

Holland, J.B., Nyquist, W.E. and CervantesMartinez, C.T. 2003. Estimating and interpreting heritability for plant breeding: An update. pp. 9-112. In: Plant Breeding Reviews. John Wiley and Sons, Inc., Hoboken, New Jersey, USA.

Hough, G., Wakeling, I., Mucci, A., Chambers, E., Gallardo, I.M. and Alves, L.R. 2006. Number of consumers necessary for sensory acceptability tests. Food Quality and Preference 17: 522-526. doi: 10.1016/j.foodqual.2005. 07.002.

International Institute of Tropical Agriculture (IITA). 1990. Cassava in tropical Africa. A reference Manual. International Institute of Tropical Agriculture (IITA), Ibadan, Nigeria. 176pp.

ISO. 1994. Sensory analysis, Methodology, Texture profile. First Edi. ISO 11036:1994(E). 56.CH-1211, Geneva 20, Switzerland. 20pp.

Kayondo, S.I., Pino, D., Carpio, D., Lozano, R., Ozimati, A., Yona, B., Gracen, V., Offei, S., Ferguson, M. and Kawuki, R. 2018. Genome-wide association mapping and genomic prediction for CBSD resistance in Manihot esculenta. Scientific Reports 8:1549: 1-11. doi: 10.1038/s41598018-19696-1.

Kombo, G.R., Dansi, A., Loko, L.Y., Orkwor, G.C., Vodouhè, R.,Assogba, P. and Magema, J.M. 2012. Diversity of cassava (Manihot esculenta Crantz) cultivars and its management in the department of
Bouenza in the Republic of Congo. Genetic Resources and Crop Evolution 59(8): 17891803. doi: 10.1007/s10722-012-9803-0.

Lebot, V. 2009. Tropical root and tuber crops: Cassava, sweet potato, yams and aroids. Crop Production Science in Horticulture (17). CABI, Wallingford, UK. 413pp.

Littell, R.C., Milliken, G.A., Stroup, W.W. and Wolfinger, R. 2006. SAS System for Mixed Models. Second Edi. SAS Publishing, Cary, NC, USA. 122pp.

Lorenzi, O. 1994. Culinary quality variation in cassava roots. Bragantia Campinas 53(2): 237-245.

Maieves, H.A., De Oliveira, D.C., Bernardo, C., Müller, C.M.D.O. and Amante, E.R. 2012. Microscopy and texture of raw and cooked cassava (Manihot esculenta Crantz) roots. Journal of Texture Studies 43(2): 164-173. doi: 10.1111/j.17454603.2011.00327.x.

Mubende District Local Government. 2013. Mubende District Local Government Statistical Abstract 2012/2013. https:// www.ubos.org/onlinefiles/uploads/ubos/ Mubende.pdf. Accessed 25 March 2019.

Nakabonge, G., Samukoya, C. and Baguma, Y. 2017. Local varieties of cassava: Conservation, cultivation and use in Uganda. Environment, Development and Sustainability. doi: 10.1007/s10668-0179997-6.

Neter, J., Kutner, M.H., Nachtsheim, C.J. and Wasserman, W. 1996. Applied Linear Statistical Models. Fourth edition. McGraw-Hill, Boston, USA. 1408pp.

Ngeve, J.M. 2003. Cassava root yields and culinary qualities as affected by harvest age and test environment. Science of Food and Agriculture 83:249-257. doi: 10.1002/ jsfa.1307.

Padonou, W., Mestres, C. and Nago, C.M. 2005. The quality of boiled cassava roots: Instrumental characterization and relationship with physicochemical properties and sensorial properties. Food 
Chemistry 89:261-270. doi: 10.1016/ j.foodchem.2004.02.033.

$\mathrm{R}$ Core Team. 2015. A language and environment for statistical computing. $\mathrm{R}$ foundation for statistical computing. Vienna, Austria. https://www.r-project.org/ Accessed 20 March 2019.

Rabbi, I.Y., Kulakow, P.A., Manu-aduening, J.A., Dankyi, A.A., Asibuo, J.Y., Parkes, E.Y., Abdoulaye, T., Girma, G., Gedil, M.A., Ramu, P., Reyes, B. and Maredia, M.K. 2015. Tracking crop varieties using genotyping- by-sequencing markers: A case study using cassava (Manihot esculenta Crantz). BMC Genetics 16:115. doi: 10.1186/s12863-015-0273-1.

Safo-kantanka, O. and Owusu-nipah, J. 1992. Cassava varietal screening for cooking quality: Relationship between dry matter, starch content, mealiness and certain microscopic observations of the raw and cooked tuber. Science of Food and Agriculture 60:99-104.

Sajeev, M.S., Sreekumar, J., Unnikrishnan, M., Moorthy, S.N. and Shanavas, S. 2010. Kinetics of thermal softening of cassava tubers and rheological modeling of the starch. Food Science Technology 47(5): 507-518. doi: 10.1007/s13197-010-00870. 